\title{
PENGARUH MODEL PEMBELAJARAN INQUIRY TRAINING \\ TERHADAP HASIL BELAJAR SISWA PADA MATERI SUHU, KALOR DAN PERPINDAHAN KALOR KELAS X SEMESTER II SMA NEGERI 1 BATANG KUIS T.P. 2014/2015
}

\author{
Sri Tuti*) dan Khairul Amdani**) (Sudah direvisi) \\ *) Mahasiswa Pendidikan Fisika UNIMED \\ **) Dosen Fisika UNIMED \\ Srituti44@yahoo.co.id \\ Jurusan pendidikan fisika FMIPA Universitas Negeri Medan
}

\begin{abstract}
ABSTRAK
Penelitian ini bertujuan untuk mengetahui pengaruh model pembelajaran inquiry training terhadap hasil belajar siswa pada materi suhu, kalor dan perpindahan kalor kelas X semester II SMA Negeri 1 Batang Kuis T.P 2014/2015. Jenis penelitian ini adalah quasi eksperimen dengan desain two group Pre-test dan Pos-test. Populasi dalam penelitian adalah seluruh siswa kelas $\mathrm{X}$ semester II SMA Negeri 1 Batang Kuis yang terdiri dari 9 kelas. Pengambilan sampel dilakukan dengan cara cluster random sampling dengan mengambil 2 kelas secara acak yaitu kelas X-9 sebagai kelas eksperimen dan kelas X-7 sebagai kelas kontrol. Instrumen penelitian adalah pilihan berganda dan lembar aktivitas siswa. Dari hasil penelitian diperoleh nilai rata-rata pretes dan postes kelas eksperimen sebesar 30,89 dan 74,89. Dan nilai rata-rata pretes dan postes kelas kontrol sebesar 31,78 dan 66,67. Rata-rata aktivitas siswa kelas eksperimen dalam kategori sangat aktif dan rata-rata aktivitas siswa kelas kontrol dalam kategori cukup aktif. Hasil uji hipotesis menggambarkan bahwa ada perbedaan akibat pengaruh penggunaan model pembelajaran inquiry training terhadap hasil belajar siswa pada materi suhu, kalor dan perpindahan kalor di kelas X semester II SMA Negeri 1 Batang Kuis T.P 2014/2015.
\end{abstract}

Kata kunci : Model pembelajaran inquiry training, aktivitas

\begin{abstract}
The purpose of this research is to know the effect of guided inquiry learning model on student's learning outcomes in topic temperature, heat and moving heat class X semester II SMA Negeri 1 Batang Kuis academic year 2014/2015. The type of research is quasi experimental research with desain two group Pre-test dan Pos-test. The population is all students of class X semester II SMA Negeri 1 Batang Kuis Academic Year 2014/2015 consist of 9 classes. Sample selected by cluster random sampling with two class are $X-9$ as experiment class and X-7 class as control class. The instrument in this research is multiple choices and observation sheet student activity. From this research get average
\end{abstract}


pre-test and pos-test experiment class were increased at 30,89 and 74,89. And average pre-test and pos-test control class were increased at 31,78 dan 66,67. Average student learning activity experiment class was very active of category and average student learning activity control class was less active of category. Result the hypothesis using test $t$ get there is the effect of guided Inquiry learning model on student's learning outcomes in topic temperature, heat and moving heat class X semester II SMA Negeri 1 Batang Kuis Academic Year 2014/2015.

Key Word : Guided Inquiry Learning Model, activity

\section{PENDAHULUAN}

Pendidikan memegang peranan penting dalam menyediakan sumber daya manusia yang berkualitas bahkan sangat menentukan keberhasilan pembangunan. Sesuai dengan amanat Peraturan pemerintah Nomor 19 Tahun 2005 tentang Standar Nasional Pendidikan, salah satu standar yang harus dikembangkan adalah standar proses. Standar proses adalah standar nasional pendidikan yang berkaitan dengan pelaksanaan pembelajaran pada satuan pendidikan untuk mencapai kompetensi lulusan. Standar proses pendidikan yang dimaksud berlaku untuk setiap lembaga pendidikan formal pada jenjang pendidikan tertentu dimana pun lembaga pendidikan itu berada secara nasional. Dengan demikian, seluruh sekolah seharusnya melaksanakan proses pembelajaran seperti yang dirumuskan dalam proses pendidikan ini. Akan tetapi, proses pembelajaran yang terjadi dalam pendidikan dewasa ini menjadi salah satu masalah yang dihadapi lembaga pendidikan formal (Sanjaya, 2010:4).

Masalah proses pembelajaran yang dihadapi dalam pendidikan formal sudah sering didengar baik di kota maupun di pedesaan, yang mengakibatkan rendahnya mutu lulusan. Dimana proses model pembelajaran konvensional dengan mengandalkan metode ceramah yang terjadi dimana-mana, tanpa mempertimbangkan berbagai faktor yang bisa mempengaruhi keberhasilan proses pembelajaran. Hal ini tampak dari rata-rata hasil belajar siswa yang senantiasa masih memprihatinkan. Prestasi ini tentunya merupakan hasil kondisi model pembelajaran yang masih konvensional atau berpusat pada guru (teacher center) yang tidak menyentuh ranah dimensi siswa itu sendiri. Seperti di ketahui, bahwa banyak mata pelajaran yang diikut sertakan dalam standar kompetensi lulusan UN (Ujian Nasional) salah satunya adalah mata pelajaran fisika.

Hal yang sama juga dijumpai disekola SMA N.1 Batang Kuis dalam matapelajaran fisika masih rendah. Rendahnya hasil belajar siswa ini disebabkan pola mengajar yang digunakan masih menggunakan metode ceramah, mencatat, dan mengerjakan soal sehingga kurang variatif dan masih cenderung konvensional. siswa menjadi tidak aktif dalam proses pembelajaran. Siswa jarang mengajukan pertanyaan dan menjawab pertanyaan, bahkan ada siswa yang tidak pernah mengajukan pertanyaan maupun menjawab pertanyaan yang diberikan guru. Hal ini terjadi karena rendahnya minat siswa dalam belajar fisika. 
Berdasarkan hasil observasi yang dilakukan oleh peneliti terhadap siswa kelas $\mathrm{X}$ di SMA Negeri 1 Batang Kuis, fisika masih dianggap sebagai mata pelajaran yang kurang menarik dan kurang menyenangkan. Hasil angket yang disebarkan kepada 35 siswa di kelas X, sebanyak 80\% siswa menganggap fisika tidak menarik dan tidak menyenangkan, $88,47 \%$ siswa menganggap fisika sulit dipahami dan membosankan. Hanya 20\% siswa yang menganggap fisika menarik dan menyenangkan, $11,43 \%$ siswa menganggap fisika tidak sulit dipahami dan tidak membosankan. Salah satu faktor yang menyebabkan siswa menganggap fisika kurang menarik dan kurang menyenangkan adalah metode mengajar yang belum tepat untuk mengajarkan fisika yang menarik bagi siswa.

Berdasarkan hasil wawancara peneliti dengan guru fisika SMA Negeri 1 Batang Kuis yaitu Ibu Dameria, S.Pd bahwa dalam melaksanakan pembelajaran beliau masih menggunakan model pembelajaran konvensional. Hasil belajar yang siswa peroleh kurang memuaskan yaitu dengan nilai ratarata harian 65 yang tidak mencapai dari nilai Kriteria Ketuntasan Minimal (KKM) mata pelajaran fisika di SMA Negeri 1 Batang Kuis yaitu 70 .

Bila masalah di atas dibiarkan terus berlanjut, dikhawatirkan tujuan pembelajaran Nasional Indonesia tidak akan tercapai. Salah satu upaya yang dapat dilakukan untuk mengatasi masalah tersebut adalah dengan menvariasikan cara pembelajaran. Perlu dilakukan pembelajaran yang melibatkan siswa dalam proses pembelajaran yang dikenal dengan pembelajaran yang perpusat pada siswa atau student centre. (Joyce, 2011:200)

Pembenahan dengan menerapkan model pembelajaran inquiry training, permasalahan tersebut diharapkan dapat teratasi. Hal ini didasarkan karena model pembelajaran inquiry training ini melibatkan siswa dalam proses pengkajian dan menjelaskan suatu fenomena khusus. Tujuannya adalah membantu siswa mengembangkan keterampilan intelektual yang diperlukan untuk mengajukan pertanyaan dan menemukan jawabannya berdasarkan rasa ingin tahunya. Melalui model pembelajaran inquiry training ini siswa diharapkan aktif mengajukan pertanyaan mengapa sesuatu terjadi kemudian mencari dan mengumpulkan serta memproses data secara logis untuk selanjutnya mengembangkan strategi intelektual yang dapat digunakan untuk menemukan jawaban atas pertanyaan mengapa sesuatu terjadi. Inquiry training dimulai dengan menyajikan peristiwa yang mengandung teka-teki atau pengetahuan bersifat tentative (tidak pasti) kepada siswa.

Berdasarkan uraian diatas, penulis berkeinginan untuk melakukan penelitian dengan judul "Pengaruh Model Pembelajaran Inquiry Training Terhadap Hasil Belajar Siswa Pada Materi Suhu, Kalor Dan Perpindahan Kalor Kelas X Semester II SMA Negeri 1 Batang Kuis T.P. 2014/2015.”

\section{Metode Penelitian}

Penelitian ini dilaksanakan di SMA Negeri 1 Batang Kuis yang beralamat di Jalan Pancasila Kec. Batang Kuis dimulai pada tanggal 
26 Maret sampai dengan 27 April 2015 .

Populasi dalam penelitian ini adalah seluruh siswa-siswi kelas $\mathrm{X}$ semester II SMA Negeri 1 Batang Kuis T.P. 2014/2015 yang terdiri dari kelas X -1 sampai kelas X -9.

Sampel dalam penelitian ini terdiri dari dua kelas yaitu kelas kontrol dan kelas eksperimen yang diambil dengan teknik cluster random sampling. Maka diperoleh kelas X -9 sebagai kelas eksperimen dengan jumlah siswa 30 orang dan kelas X X -7 sebagai kelas control dengan jumlah siswa 30 orang.

Instrumen yang digunakan adalah tes hasil belajar siswa dan observasi aktivitas siswa. Tes hasil belajar siswa berjumlah lima belas (15) soal dalam bentuk pilihan berganda. Tes ini diberikan sebanyak 2 kali yaitu pada saat pretes dan postes. Sedangkan observasi yang dimaksud dalam penelitian ini adalah observasi yang dilakukan untuk mengamati keseluruhan aktivitas belajar siswa selama pelaksanaan proses pembelajaran.

Penelitian ini melibatkan dua kelas yang diberi perlakuan yang berbeda. Satu kelas dijadikan kelas eksperimen dan satu kelas lainnya dijadikan kelas kontrol. Untuk mengetahui hasil belajar siswa diberikan perlakuan yang berbeda pada kedua kelas tersebut. Rancangan penelitian ini sebagai berikut:

Tabel 1. Two Group Pretes Posttest Design

\begin{tabular}{|c|c|c|c|}
\hline Kelas & Pretes & Perlakuan & Postes \\
\hline Eksperimen & $\mathrm{T}_{1}$ & $\mathrm{X}_{1}$ & $\mathrm{~T}_{2}$ \\
\hline Kontrol & $\mathrm{T}_{1}$ & $\mathrm{X}_{2}$ & $\mathrm{~T}_{2}$ \\
\hline
\end{tabular}

Dengan:

$\mathrm{X}_{1}=$ Pembelajaran dengan menggunakan model pembelajaran inquiry training

$\mathrm{X}_{2}=$ Pembelajaran dengan menggunakan pembelajaran konvensional.

$\mathrm{T}_{1}=$ Pretes diberikan kepada kelas eksperimen dan kelas kontrol sebelum perlakuan.

$\mathrm{T}_{2}=$ Postes diberikan setelah perlakuan pada kelas eksperimen dan kelas control

Dari hasil pretest yang dipeoleh dilakukan uji Normalitas dan uji kesamaan rata-rata (uji t) untuk menentukan apakah data berdistribusi normal dan apakah ada perbedaan yang signifikan antara hasil belajar kedua kelas. Selanjutnya kedua kelas diberi perlakuan yang berbeda. Setelah itu kedua kelas diberi postes. Dari hasil postes yang diperoleh dilakukan uji kesamaan rata-rata (uji t) untuk menunjukkan bahwa ada pengaruh atau tidak model pembelajaran inquiry training terhadap hasil belajar siswa.

untuk $\begin{array}{cr}\text { Observasi } & \text { dimaksudkan } \\ \text { mengamati } & \text { keseluruhan }\end{array}$ aktivitas belajar siswa selama pelaksanaan proses pembelajaran. Observasi aktivitas siswa dalam proses pembelajaran dilakukan agar mengetahui apakah model pembelajaran inquiry training yang diterapkan mengakibatkan timbulnya berbagai aktivitas siswa. Untuk menentukan taraf aktivitas proses belajar siswa dengan nilai yang dicapai adalah :

Kriteria aktivitas $=\frac{\text { Skor tertinggi }}{\text { Jumlah } \text { kriteria }}$ 
Tabel 2. Taraf Aktivitas Siswa

\begin{tabular}{|l|l|}
\hline Interval & Kriteria \\
\hline $541-720$ & Sangat Aktif \\
\hline $361-540$ & Cukup Aktif \\
\hline $181-360$ & Kurang Aktif \\
\hline $0-180$ & Tidak Aktif \\
\hline
\end{tabular}

\section{HASIL DAN PEMBAHASAN}

Penelitian diawali dengan memberikan pretes terhadap kedua sampel dengan jumlah soal 15 soal dalam bentuk pilhan berganda yaitu pada kelas eksperimen dan kelas kontrol. Berdasarkan data hasil penelitian diperoleh nilai rata-rata pretes siswa pada kelas eksperimen sebelum diberi perlakuan dengan menggunakan model pembelajaran inquiry training sebesar 30,89 dengan standar deviasi 10,86. Sedangkan di kelas kontrol diperoleh nilai rata-rata pretes siswa sebesar 31,78 dengan standar deviasi 13,06.

Kemudian pada kedua kelas diberi perlakuan yang berbeda yaitu pada kelas eksperimen diberi perlakuan menggunakan model pembelajaran inquiry training sedangkan kelas kontrol diberi perlakuan dengan menggunakan model pembelajaran konvensional. Setelah kedua kelas diberikan perlakuan yang berbeda, kedua kelas selanjutnya diberikan postes dengan soal yang sama dengan soal pretes. Hasil yang diperoleh adalah, nilai rata-rata postes kelas eksperimen setelah dibelajarkan model pembelajaran inquiry training sebesar 74,89 dengan standar deviasi 13,30. Sedangkan di kelas kontrol diperoleh nilai rata-rata postes siswa sebesar 66,67 dengan standar deviasi 12,98

Hasil uji normalitas untuk kedua sampel menunjukkan bahwa kedua kelas berdistribusi normal dimana $\mathrm{L}_{\text {hitung }}<\mathrm{L}_{\text {tabel }}$ dan berasal dari populasi yang homogen. Hasil uji hipotesis untuk postes menggunakan uji $t$ pada taraf signifikan $\alpha=0,05$ diperoleh $t_{\text {hitung }}>$ $t_{\text {tabel }}(2,42>1,67)$ yang berarti bahwa ada perbedaan akibat pengaruh model pembelajaran inquiry training terhadap hasil belajar siswa pada materi suhu, kalor dan perpindahan kalor.

Penelitian ini sejalan dengan hasil penelitian yang dilakukan oleh Retno Sari P. (2014:1), diperoleh pembelajaran Inquiry Training Model dapat meningkatkan motivasi belajar siswa dan pemahaman konsep fisika siswa. Penelitian yang dilakukan oleh Trisno, dkk (2012:19), diperoleh hasil penelitian dengan menunjukkan terdapat perbedaan hasil belajar siswa yang mengikuti model pembelajaran inquiry training dengan siswa yang mengikuti model pembelajaran konvensional.

Aktivitas siswa selama proses pembelajaran juga diamati. Aspek aktivitas yang dinilai antara lain: Menjawab Pertanyaan, Bertanya kepada Guru, Merumuskan Hipotesis, Mengumpulkan dan Menganalisis Data, Menyajikan hasil kerja, dan Membuat Kesimpulan. Observasi dilakukan selama kegiatan belajar mengajar yang terdiri dari empat kali pertemuan yang dilakukan oleh dua observer yaitu rekan sejawat. Dalam penelitian ini, peningkatan yang terjadi setiap pertemuan pembelajaran. 


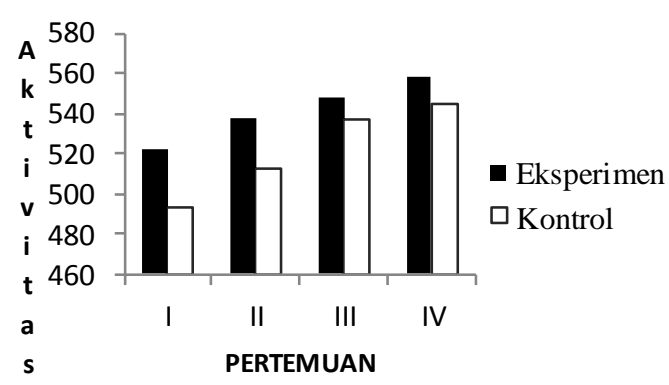

Gambar 3. Peningkatan Aktivitas pada Kelas Eksperimen dan Kelas Kontrol

Berdasarkan Gambar 3. dapat dilihat bahwa rata-rata peningkatan aktivitas belajar siswa di kelas eksperimen lebih tinggi daripada kelas kontrol. Hal ini menunjukkan bahwa penerapan model pembelajaran yang dilakukan di kelas eksperimen lebih baik daripada kelas kontrol yaitu dengan model pembelajaran inqury training, dengan model ini aktivitas siswa meningkat karena dalam setiap tahap pembelajaran mengharuskan siswa untuk sangat aktif dalam belajar.

Penelitian ini juga sejalan dengan penelitian yang dilakukan oleh Toenas, dkk (2012:258), diperoleh bahwa terdapat interaksi antara model pembelajaran inquiry training melalui teknik peta konsep dan teknik puzzle dengan keberagaman aktivitas belajar dan keberagaman kemampuan memori terhadap prestasi belajar. Selain itu, penelitian yang dilakukan oleh Azizah dan Parmin (2012:11), Dari hasil penelitian yang telah diperoleh menunjukkan bahwa aktivitas keterampilan mahasiswa dapat ditingkatkan dengan menerapkan inquiry training.

\section{KESIMPULAN DAN SARAN}

\section{Kesimpulan}

Berdasarkan hasil penelitian yang diperoleh dari hasil analisis data dan pengujian hipotesis maka dapat disimpulkan sebagai berikut : (1) Hasil belajar siswa yang dibelajarkan dengan menggunakan model pembelajaran inquiry training pada materi suhu, kalor dan perpindahan kalor memperoleh nilai rata-rata 74,89 yang memenuhi Kriteria Ketuntasan Minimal (KKM) yakni 70 sebesar 76,67\%. (2) Hasil belajar siswa yang dibelajarkan dengan menggunakan model konvensional pada kelas kontrol memperoleh nilai rata-rata 66,67 yang memenuhi Kriteria Ketuntasan Minimal (KKM) yakni 70 sebesar 40\%. (3) Ada perbedaan hasil belajar siswa akibat pengaruh model pembelajaran inquiry training dengan model pembelajaran konvensional. (4) Aktivitas belajar siswa yang dibelajarkan dengan menggunakan model pembelajaran inquiry training yang memperoleh nilai rata - rata keseluruhan sebesar 541,98 dengan kriteria sangat aktif dan aktivitas belajar siswa yang dibelajarkan dengan menggunakan model pembelajaran konvensional yang memperoleh nilai rata - rata keseluruhan 522 dengan kriteria cukup aktif.

\section{Saran}

Berdasarkan hasil dan kesimpulan dalam penelitian ini, maka peneliti mempunyai beberapa saran, yaitu: (1) Kepada peneliti selanjutnya yang ingin meneliti tentang model pembelajaran inquiry training ini agar peneliti lebih membimbing siswa dengan cara aktif bertanya kepada siswa tentang kendala yang dihadapi, memotivasi, 
dan mengarahkan agar setiap siswa aktif berdiskusi. (2) Kepada peneliti selanjutnya yang ingin meneliti tentang Model Pembelajaran Inquiry Training, ada baiknya memberikan motivasi agar siswa merasa percaya diri untuk bertanya dan menjawab persoalan di dalam kelas. (3) Kepada peneliti selanjutnya yang ingin meneliti model yang sama disarankan melakukan penelitian pada lokasi dan materi pokok yang berbeda serta terlebih dahulu memperhatikan kelemahankelemahan dalam penelitian ini untuk memperoleh hasil belajar yang lebih baik

\section{DAFTAR PUSTAKA}

Azizah, A., dan Parmin,(2012), Online Physics Module : Inquiry Training Untuk Mengembangkan

Keterampilan Meneliti Mahasiswa, Journal of Unnes Science Education 1(1):22526617

Joyce, B., Weil, M., dan Calhoun, E., (2011), Model-Model Pembelajaran, Edisi Kedelapan, Pustaka Belajar, Yogyakarta.

Sanjaya,W., (2010), Strategi Pembelajaran Berorientasi Standar Proses Pendidikan, Kencana, Jakarta.

Sari, R. P., (2014), Online Physics Module : Penerapan Inquiry Training Model Untuk Meningkatkan Motivasi Belajar dan Pemahaman Konsep Fisika Siswa Kelas $\begin{array}{llll}\text { VIII } & \text { F } & \text { SMPN } & 1\end{array}$
KARANGPLOSO, Jurnal Universitas Negeri Malang

Toenas, (2012), Online Physics Module: Penerapan Model Inquiry Training Melalui Teknik Peta Konsep dan Teknik Puzzle Ditinjau dari Tingkat Keberagaman Aktivitas Belajar dan Kemampuan Memori, Jurnal. Pasca. Uns. Ac. Id 1(3):258265

Trisno, Yusuf K., dan Marungkil P., (2012), Online Physics Module : Pengaruh Model Pembelajaran Training Inquiry Terhadap Hasil Belajar Pada Pokok Bahasan Kalor Siswa SMP Negeri 9 Palu, Journal of Tadulako Science Education 2(1 ):1420 